\title{
Quality of life in patients with leg ulcers or skin lesions - a pilot study
}

\author{
Maria T. Szewczyk ${ }^{1,2}$, Paulina Mościcka ${ }^{1,2}$, Arkadiusz Jawień², Justyna Cwajda-Białasik ${ }^{1}$, Katarzyna Cierzniakowska ${ }^{1,2}$, \\ Robert Ślusarz ${ }^{3}$, Elżbieta Hancke²
}

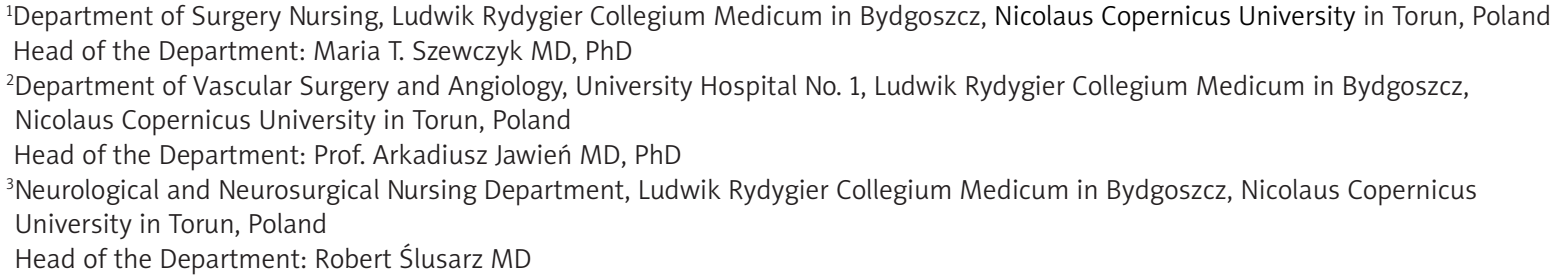

Postep Derm Alergol 2015; XXXII (6): 465-469

DOI: $10.5114 /$ pdia.2014.40983

\begin{abstract}
Introduction: Attempts to determine the quality of life are advisable in patients with ulcers as the group affected with this problem is relatively large. According to one Polish randomized trial, approximately $0.3-2 \%$ of the adult population suffers from active or healed venous ulcers.

Aim: To compare the quality of life of patients with leg ulcers of venous and arterial etiology and those with lower limb skin lesions due to chronic venous insufficiency.

Material and methods: This study included 90 consecutive patients with ulcers of venous $(n=30)$ or arterial etiology $(n=30)$, or patients with trophic disorders of the skin associated with chronic venous insufficiency $(n=30)$ treated at the Venous Ulceration Outpatient Clinic and at the Department and Clinic of General Surgery, Dr. J. Biziel Memorial University Hospital No. 2, in Bydgoszcz. This study was designed as a questionnaire survey and included the Skindex-29 instrument for the assessment of quality of life in patients with dermatological conditions.

Results: Overall, the global Skinndex-29 scores of all studied participants ranged between 37 and 136 points, 23.93 points on average. The analyzed groups of patients differed significantly with respect to the average level of the global quality of life determined using the Skindex-29 questionnaire.

Conclusions: Significant differences were observed in the global quality of life of patients who suffered from venous or arterial leg ulcers or skin lesions resulting from chronic venous insufficiency.
\end{abstract}

Key words: health-related quality of life, Skindex-29, leg ulcers.

\section{Introduction}

Quality of life is closely associated with a widely understood definition of health described by the World Health Organization as "a state of complete physical, mental, and social well-being and not merely the absence of disease or infirmity" [1, 2]. The quality of life gains a particular importance when it is assessed in the context of a chronic disorder. It can be equally or even more important than a biomedical improvement since both the disease itself and its treatment always affect the physical, mental, and social dimension of one's functioning.

Individuals with crural ulcers, not infrequently subjected to chronic and not always efficient therapies, constitute a specific group of patients. Most commonly, chronic wounds of the lower limbs result from venous (70-80\%) and arterial disorders (10-15\%). Lesions resulting from chronic venous insufficiency and lower limb atherosclerosis usually are chronic and progressive. The presence of the ulcer is associated with changes in patient's outward appearance and self-perception and, therefore, can negatively affect the quality of life [3-5]. Additionally, all spheres of life are modulated by chronic and expensive treatment, absence from work, and, sometimes, also by the disability pension $[6,7]$. Attempts to determine the quality of life are advisable in patients with ulcers as the group affected with this problem is

Address for correspondence: Maria T. Szewczyk MD, PhD, Department of Surgery Nursing, Ludwik Rydygier Collegium Medicum in Bydgoszcz, Nicolaus Copernicus University in Torun, 1 Łukasiewicza St, 85-821 Bydgoszcz, Poland, phone: +485258540 40, fax: +485258558 09, e-mail: mszewczyk@cm.umk.pl

Received: 8.11.2013, accepted: 25.01.2014. 
relatively large. According to one Polish randomized trial, approximately $0.3-2 \%$ of the adult population suffers from active or healed venous ulcers [8].

\section{Aim}

The aim of this study was to compare the quality of life of patients with leg ulcers of venous and arterial etiology and those with lower limb skin lesions due to chronic venous insufficiency.

\section{Material and methods}

The study included 90 consecutive patients treated between 2008 and 2009 at the Venous Ulceration Outpatient Clinic and at the Department and Clinic of General Surgery of Dr. J. Biziel Memorial University Hospital No. 2 in Bydgoszcz. This group included 60 patients with leg ulcers, i.e. discontinuity of the skin associated with the loss of tissue, among them 30 individuals with ulcers of venous etiology (chronic venous insufficiency - CVI; anklebrachial index within the normal range, i.e. 0.9-1.3) and 30 subjects with the ulcers of arterial etiology (lower limb atherosclerosis - LLA; values of the ankle-brachial index $\leq 0.9$, suggesting ischemia of the lower extremities), as well as 30 patients with trophic disorders of the skin associated with chronic venous insufficiency (discoloration, spots, dryness, and peeling). Inclusion criteria comprised established medical diagnosis of an underlying primary condition. Exclusion criteria included age below 18 years, ulcers of non-arterial, non-venous or unknown etiology, chronic comorbidities other than CVI and LLA, and incomplete medical documentation.

Detailed characteristics of study participants are summarized in Table 1.

The protocol for this study was accepted by the Local Bioethical Committee at the L. Rydygier Collegium Medicum in Bydgoszcz, Nicolaus Copernicus University in Torun.

\section{Study instruments}

This study was designed as a questionnaire survey and included the Skindex-29 instrument for the assessment of the quality of life of patients with dermatological conditions [9]. The Polish version of the questionnaire, adapted in 1999 with the approval of the original instru- ment's authors, was used [10]. The questionnaire was completed by participants at the Clinic during routine visits.

The Skindex-29 questionnaire includes 29 statements dealing with the potential effects of the dermatological condition on various components of quality of life: A) physical symptoms, involving the skin, B) the emotional sphere, and C) the psychosocial functioning $[9,10]$.

The respondents scored the aforementioned parameters with regard to the month preceding the study, giving the frequency (never, rarely, sometimes, frequently, all the time) with which they have experienced any of the feelings listed in the questionnaire. The answers were assigned scores ranging between 1 and 5 points depending on the frequency of feelings experienced by the subject (never = 1 point; rarely = 2 points; sometimes $=3$ points; frequently $=4$ points; all the time $=5$ points). The respondent's quality of life was expressed as the sum of points, ranging between 29 , corresponding to the highest quality - lack of negative effects of the condition, and 145 , corresponding to the lowest quality - maximal negative influence of the condition.

Skindex-29 scores of the quality of life were interpreted as follows:

- 29 to 58 points indicated high quality of life (25\%),

- 59 to 87 points corresponded to moderate quality of life (26-50\%),

$->87$ points corresponded to low quality of life (above $50 \%)$.

Specific dimensions of the quality of life were interpreted in an analogous way with regard to physical symptoms (between 7 and 35 points), the emotional sphere (10-50 points), and the psychosocial functioning (12-60 points).

\section{Statistical analysis}

Statistical characteristics of the continuous variables were presented as arithmetic means and their standard deviations (SD) or as medians and interquartile ranges. The values of continuous variables in patients with ulcers of various etiologies were compared using the Kruskal-Wallis test. The power and direction of the relationships between analyzed variables were determined using the non-parametric Spearman's test. All calculations were carried out using Statistica 7 (StatSoft ${ }^{\oplus}$ ) package with a level of significance set at $p \leq 0.05$.

Table 1. Characteristics of the studied group

\begin{tabular}{lcccc}
\hline Parameter & All patients & Venous ulcerations & Arterial ulcerations & Trophic disorders of the skin \\
\hline Women, $n(\%)$ & $59(65.56)$ & $20(66.67)$ & $16(53.33)$ & $23(76.67)$ \\
\hline Men, $n(\%)$ & $31(34.44)$ & $10(33.33)$ & $14(46.67)$ & $7(23.33)$ \\
\hline Total, $n(\%)$ & $90(100)$ & $30(100)$ & $30(100)$ & $30(100)$ \\
\hline Age, mean [years] & 68.31 & 66.53 & 68.07 & 70.33 \\
\hline
\end{tabular}




\section{Results}

Overall, the global Skinndex-29 scores of all studied participants ranged between 37 and 136 points, 23.93 points on average.

The analyzed groups of patients differed significantly with respect to the average level of the global quality of life determined using the Skindex-29 questionnaire. A significant relationship between the quality of life level and the type of skin lesion was revealed. Patients with ulcers of arterial etiology represented the lowest level of the quality of life (as suggested by higher values of the Skindex-29 score), followed by patients with venous ulcers who represented the moderate level, and individuals with trophic disorders without the discontinuity of the skin, whose quality of life was the highest, as suggested by lower values of the Skindex-29 score. The quality of life in this group was at the threshold value of high level (average global Skindex-29 score: 61.17 points). More than a half of the patients (53.3\%) were characterized by a high perception of the quality of life and only 4 (13.3\%) individuals represented a low level of this parameter. The average global Skindex-29 score of patients with ulcers of venous etiology was 87.03 points. In half of the participants from this group (50\%), the quality of life was found to be moderate, while 14 (46.7\%) individuals were characterized by a low quality of life level. The average global Skindex-29 score of arterial ulcer patients was 92.67 points. The quality of life was shown to be low in as many as 20 individuals with ulcers of arterial etiology (66.7\%), and a high level of this parameter was represented by only 3 participants from this group (10\%). Detailed distributions of the global quality of life scores are summarized in Table 2.

Detailed analysis of the Skindex-29 subscales revealed that the analyzed groups did not differ significantly in terms of mean levels of the quality of life regarding emotional sphere and psychosocial functioning. In contrast, participants from various groups differed significantly in terms of the average quality of life related to physical symptoms. The average level of this dimension was the highest in patients with retained continuity of the skin, as suggested by the lowest value of the Skindex-29 scale, 17.43 points on average. The remaining two groups of patients, individuals with ulcers of venous (mean:
$23.83 \%$ ) and arterial etiology (mean: $24.03 \%$ ), represented low levels of the quality of life (24.03 points on average; $r=0.53740, p<0.05$; Figure 1).

Furthermore, patients without ulcers were characterized by the highest levels of the quality of life related to psychosocial and emotional spheres; however, these intergroup differences did not prove significant on statistical analysis.

\section{Discussion}

In the last several years, increasing attention has been paid not only to the administration of life-saving treatment but also to the patient's quality of life. The quality of life is of a particular importance in the course of chronic disorders, including such skin lesions as leg ulcers. Most of the skin lesions, including the lesions resulting from impaired circulation of the lower limbs, do not constitute a direct threat to life, which may lead to trivializing the problems reported by patients suffering from such conditions. Nevertheless, literature data suggest that dermatological conditions can deteriorate one's quality of life, by changing patient's outward appearance, depressing the mood, enhancing sensitivity of the skin, and limiting professional, social, and familial relationships $[4,11,12]$.

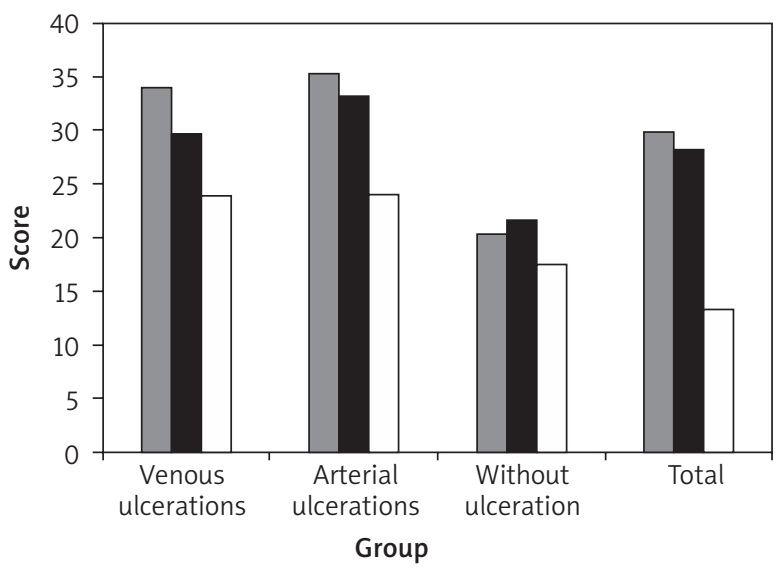

$\square$ Psychosocial sphere Emotional sphere $\quad$ Physical sphere

Figure 1. Mean values of the quality of life scores related to psychosocial, emotional, and physical spheres

Table 2. Mean values of the global quality of life (QoL) scores

\begin{tabular}{|c|c|c|c|c|c|c|c|c|c|}
\hline \multirow[t]{2}{*}{ Patients } & \multicolumn{2}{|c|}{ High QoL } & \multicolumn{2}{|c|}{ Moderate QoL } & \multicolumn{2}{|c|}{ Low QoL } & \multicolumn{3}{|c|}{ Total } \\
\hline & $n$ & $\%$ & $n$ & $\%$ & $n$ & $\%$ & $n$ & Min. & Max. \\
\hline Venous ulcerations & 1 & 3.3 & 15 & 50.0 & 14 & 46.7 & 87.03 & 57 & 123 \\
\hline Arterial ulcerations & 3 & 10.0 & 7 & 23.3 & 20 & 66.7 & 92.67 & 38 & 136 \\
\hline Without ulceration & 16 & 53.3 & 10 & 33.3 & 4 & 13.3 & 61.17 & 37 & 113 \\
\hline Total & 20 & 22.2 & 32 & 35.6 & 38 & 42.2 & 80.29 & 37 & 136 \\
\hline
\end{tabular}


One study compared the global quality of life scores in patients with and without ulcers as well as the levels of this quality in three spheres: psychosocial, physical, and emotional. Compared to ulcer-free individuals, patients with ulcers were characterized by lower global quality of life scores. In our study, the average global Skindex-29 scores of 87.03 points in venous ulcer patients and 92.67 points in individuals with ulcers of arterial etiology corresponded to a moderate and low level of the quality of life, respectively; the average score of ulcer-free patients (61.17 points) indicated moderate/ high quality of life. Moreover, individuals with ulcers were characterized by higher levels of the quality of life related to psychosocial, physical, and emotional spheres.

The Skindex-29 questionnaire was previously used in the determination of quality of life in dermatological patients [11, 13-15]. This instrument was used for the first time in 2007 to evaluate the quality of life of British ulcer patients [16]: the results of our study correspond to those obtained in the course of their experiment. Our findings were also compared to another study that employed a different instrument to compare the quality of life of venous ulcer patients and ulcer-free patients. Compared to individuals without ulcers, patients with ulcers were characterized by a lower level of the quality of life; correspondingly, subjects without ulcers showed lower quality of life than healthy individuals [17]. Similar findings were reported by Phillips et al. in 1994 [6].

\section{Physical sphere}

Literature emphasizes that trophic lesions of the skin are frequently associated with pain and other physical symptoms, such as abundantly oozing and unpleasantly smelling wound $[3,7]$. Previous studies identified factors and physical complaints that can diminish the quality of life of ulcer patients, including wound pain [6], pain and itchiness of the skin [18], exudate [6], unpleasantly smelling wound $[16,18]$, and pain- $[17,18]$ or joint deformationrelated diminishing of physical activity $[19,20]$.

In one study, including patients with ulcers of venous, atherosclerotic, and diabetic etiology, $96.7 \%$ of the participants experienced pain and more than $46 \%$ of subjects declared that the pain exacerbated upon touch [21]. In the study by Walshe, pain represented one of the main problems reported by ulcer patients. The participants described it as "unbearable pain" or "tear-inducing pain" [7]. In the study by Szewczyk et al., 72\% of the participants experienced constraints of physical activity and pain-related dependence on others $[5,20]$. According to other authors, the reason for the limited mobility is also the need for frequent dressing changes, which may cause reluctance to stay outside of home, or by the need for prevention [16]. Other authors observed that the limited motor activity of ulcer patients and their reluctance to leave home was caused by intense exudate and unpleasant smell of the wound [17]. A study of functional capacity of patients with chronic venous insufficiency and crural ulcers, conducted in the Bydgoszcz facility with the use of $A D L$ questionnaire, revealed that patients with leg ulcers showed significantly lower levels of functional capacity as compared to their healthy peers [5]. Also, patients with ulcers that participated in our study were characterized by a lower level of the quality of life related to the physical sphere as compared to ulcer-free individuals.

\section{Psychosocial sphere}

Emphasis is placed on the negative impact of ulcers on the social functioning of patients with dermal lesions that include changes pertaining to spheres such as professional activity [3], closeness with others [7, 16], social life [16, 18], and social isolation $[6,17]$. The disease and its consequences enforce modification of previous social and professional roles $[3,6]$. Frequently, inappropriate therapy of ulcers results in prolonged and expensive treatment, significantly burdening national and patient's budgets. In the study by Szewczyk et al., 52\% of the patients received disability pension; ulcers constituted the main reason for retiring from professional activities for $50 \%$ of them, while $85.7 \%$ of the subjects had to temporarily quit their jobs due to their condition [3]. The study by Chase, using the SF-36 questionnaire, revealed that ulcers are associated with a reduction in performed work [22]. Patients participating in Walshe's study avoided contacts with other people due to unpleasant smell of wound exudate, which was compared to "leprosy, negatively perceived by the society". Another reason for reducing or avoiding contact with other people was the fear of mechanic trauma to the area of the wound [7]. Szewczyk et al. observed that in $34 \%$ of the patients the presence of skin lesions affected the relationship with newly-met individuals, while $20 \%$ and $4 \%$ of the patients reduced their contacts with friends and close family members, respectively [3].

Despite the chronic and esthetically-impairing status of the disease, patients with ulcers should strive towards achieving stable and satisfactory psychosocial status [7, 15].

Skindex-29 questionnaire used in this study still has not found a wide-spread use in the examination of patients with ulcers. Nevertheless, studies involving other instruments showed similar relationships as those described by us in this paper.

\section{Emotional sphere}

Skin constitutes an important means of emotional expression and perception. Consequently, any disorder of the skin is reflected by emotional limitation and disability. Patients with ulcers frequently experience negative emotions such as shame, embarrassment [3, 7, 18], depression [23], worry that the condition may get worse [18], wrath, anger [7, 23], apathy, and mental and motor unrest $[4,11,12,13]$. According to Steuden and Janowski, negative emotions co-exist with a strong feeling of loneliness in dermatological patients. The intensity of this feel- 
ing increases in concert with greater disorganization of psychosocial functioning and higher prevalence of emotional problems [13]. Szewczyk observed that patients with leg ulcers experienced depressed mood (54\%), mood changes (34\%), irritation (30\%), and anxiety (12\%) $[3,20]$. Other authors revealed that ulcer patients tried to hide their affected limbs, wearing long pants and socks $[6,7,16,23]$. Our study revealed that the negative impact of skin lesions on the quality of life related to the emotional sphere was more pronounced in ulcer patients. Progressive and chronic character of skin lesions affects the most important spheres of human life, and disturbing any of them brings specific consequences [24, 25]. Patients with skin lesions require comprehensive care to cover all aspects of impaired functioning in physical, psychosocial and emotional spheres.

\section{Conclusions}

This study documented the effect of trophic changes of the skin on the global quality of life. Significant differences were observed in the global quality of life of patients who suffered from venous or arterial leg ulcers or skin lesions due to chronic venous insufficiency. UIcers exerted a significantly stronger negative effect on the global quality of life and functioning in the physical sphere as compared to trophic lesions without the loss of tissue and disrupted continuity of the skin. A lower level of the quality of life associated with the physical sphere suggests that aside from the activities aimed at healing the ulcer, also those oriented at minimizing the subjectively-perceived symptoms and complaints should be included in the treatment protocol. Therefore, patients with ulcers should be offered comprehensive care taking their subjective expectations into account.

\section{Conflict of interest}

The authors declare no conflict of interest.

\section{References}

1. Leplège A, Hunt S. The problem of quality of life in medicine. JAMA 1997; 278: 47-50.

2. World Health Organization Working Group. The WHO quality of life assessment instrument. In: Quality of Life Assessment in Health Care Settings. Orley J, Kuyken W (eds). SpringerVerlag, Heidelberg 1994; 1-13.

3. Szewczyk MT, Rogala J, Cwajda J, et al. Psychological and social problems of patients with chronic venous disease. Postep Derm Alergol 2007; 24: 207-10.

4. Potocka A, Turczyn-Jabłońska K, Kieć-Świerczyńska M. Selfimage and quality of life of dermatology patients. Int J Occup Med Environ Health 2008; 21: 309-17.

5. Szewczyk MT, Jawień A, Cierzniakowska K, et al. Evaluation of functional activity of patients with chronic venous insufficiency and leg ulcer. Postep Derm Alergol 2005; 22: 265-70.

6. Phillips T, Stanton B, Provan A, Lew R. A study of the impact of leg ulcers on quality of life: financial, social, and psychologic implications. J Am Acad Dermatol 1994; 31: 49-53.
7. Walshe C. Living with a venous leg ulcer: descriptive study of patients' experiences. J Adv Nursing 1995; 22: 1092-100.

8. Jawień A, Grzela T, Ochwat A. Prevalence of chronic venous insufficiency (CVI) in men and woman of Poland. Multicenter cross-sectional study of 40095 patients. Phlebology 2003; 3: 110-22.

9. Chren MM, Lasek RJ, Quinn LM, et al. Skindex, a qualityof-life measure for patients with skin diseases: reliability, validity and responsiveness. J Investig Dermatol 1996; 107: 707-13.

10. Janowski K. Osobowościowe uwarunkowania radzenia sobie ze stresem w łuszczycy. Dissertation. Wyd. Polihymnia. KUL, Lublin 2006.

11. Świnoga M, Kłos M, Miniszewska J, Zalewska-Janowska A. Health-related quality of life in dermatological and allergodermatological patients. Postep Derm Alergol 2012; 29: 69-73.

12. Kowalewska B, Krajewska-Kułak E, Wrońska I, et al. Selfevaluation of quality of life by patients with skin problems. Dermatol Klin 2010; 12: 106-13.

13. Steuden S, Janowski K. Zastosowanie kwestionariusza Skindex do pomiaru jakości życia u pacjentów z łuszczycą. Przegl Dermatol 2001; 88: 41-8.

14. Nijsten TEC, Sampogna F, Chren MM, Abeni DD. Testing and reducing Skindex-29 using rash analysis: Skindex-17. J Invest Dermatol 2006; 126: 1244-50.

15. Yi Zhi Lau M, Burgess JA, Nikson R, et al. A review of the impact of occupational contact dermatitis on quality of life. J Allergy 2011; 2011: 964509.

16. Hareendran A, Doll H, Wild DJ, et al. The venous leg ulcer quality of life (VLU-QoL) questionnaire: development and psychometric validation. Wound Rep Reg 2007; 15: 465-73.

17. Palfreyman SJ. Assessing the impact of venous ulceration on quality of life. Nursing Times 2008; 104: 34-7.

18. Byrne O, Kelly M. Living with a chronic leg ulcer. J Commun Nurs 2010; 24: 4-9.

19. Skavberg Roaldsen K, Biguet G, Elfving B. Physical activity in patients with venous leg ulcer - between engagement and avoidance. A patient perspective. Clin Rehabil 2011; 25: 275-86.

20. Jawień A, Szewczyk M, Kędziora-Kornatowska K, et al. Functional and biopsychosocial restrictions among patients with a venous ulcer. Arch Med Sci 2006; 2: 34-41.

21. Białasik B, Muszalik M, Szewczyk MT. Evaluation of pain among patients with leg ulcers. Pielęgn Chir Angiol 2007; 4: $15-157$

22. Chase SK, Whittemore R, Crosby N, Freney D. Living with chronic venous leg ulcers: a descriptive study of knowledge and functional health status. J Comm Health Nursing 2000; 17: 1-13.

23. Cole-King A, Harding KG, Psychological factors and delayed healing in chronic wounds. Psychosom Med 2001; 63: 216-20.

24. Jankowiak B, Sekmistrz S, Kowalewska K, et al. Satisfaction with life in a group of psoriasis patients. Postep Derm Alergol 2013; 30: 85-90.

25. Molski P, Kruczyński J, Molski A, Molski S. Manual lymphatic drainage improves the quality of life in patients with chronic venous disease: a randomized controlled trial. Arch Med Sci 2013; 9: 452-8. 